\title{
OTOMATISASI ALAT PENGEPAKAN PERMEN SKALA HOME INDUSTRI BERBASIS MIKROKONTROLER ATMEGA 8535
}

\author{
Dony Hardika Arfianto, Subali \\ Program Studi Diploma III Teknik Elektro \\ Fakultas Teknik Universitas Diponegoro
}

\begin{abstract}
Dony Hardika Arfianto, Subali, in paper candy automation packing at home industry use ATMEGA 8535 microcontroller explain that in this modernization era, almost all activity uses of automation, both in the industrial middle, upper and home industry. If the process of candy packing can be automated it will be very advantageous for industrial-scale home industry. This candy packaging automation systems using a microcontroller ATmega 8535. The tool consists of a sensor LDR as sensor packaging, the heater as a tool for plastics pressing, conveyor as a driver and microcontroller ATmega 8535 as the main controller. Microcontroller ATmega8535 is one of the artificial Atmel microcontroller that has many uses. Price microcontroller is relatively cheap nowadays, if viewed from its facilities.
\end{abstract}

Keywords: packing, LDR sensor, heater, microcontroller ATmega8535

\section{PENDAHULUAN}

Pengepakan adalah kegiatan membungkus atau menutupi dengan pembungkus (penutup) yang memenuhi persyaratan produksi. Proses pengepakan permen ke dalam wadah yang dilakukan secara manual sangatlah tidak efisien dan membutuhkan waktu yang relatif lama. Jika proses tersebut dapat diotomatisasikan akan sangat menguntungkan bagi industri yang berskala home industry. Sistem otomatisasi pengepakan permen ini menggunakan mikrokontroler.

Mikrokontroler adalah salah satu dari bagian dasar dari suatu sistem komputer. Meskipun mempunyai bentuk yang jauh lebih kecil dari suatu komputer pribadi dan komputer mainframe, mikrokontroler dibangun dari elemen-elemen dasar yang sama. Seperti umumnya komputer, mikrokontroler adalah alat yang mengerjakan instruksi-instruksi yang diberikan kepadanya. Artinya, bagian terpenting dan utama dari suatu sistem terkomputerisasi adalah program itu sendiri yang dibuat oleh seorang programmer. Program ini menginstruksikan komputer untuk melakukan jalinan yang panjang dari aksi-aksi sederhana untuk melakukan tugas yang lebih kompleks yang diinginkan oleh programmer.

\section{CATU DAYA}

Perangkat elektronika mestinya dicatu oleh suplai arus searah DC (direct current) yang stabil agar dapat bekerja dengan baik. Untuk itu diperlukan suatu perangkat catu daya yang dapat mengubah arus AC menjadi DC.

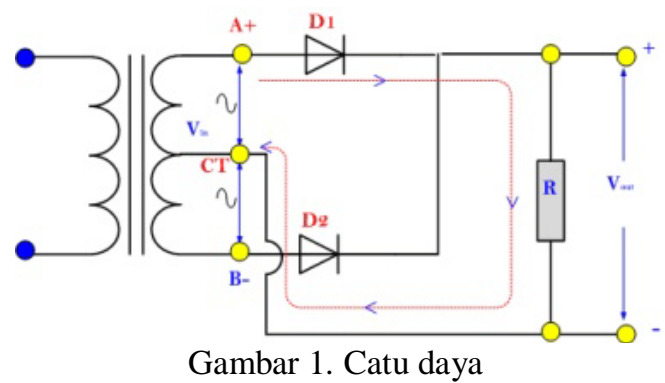

\section{DRIVER}

Driver merupakan salah satu perangkat umum yang digunakan untuk kendali motor DC. Driver motor ini yang nantinya bertugas mengendalikan arah putaran maupun kecepatan motor DC yang akan dikendalikan.

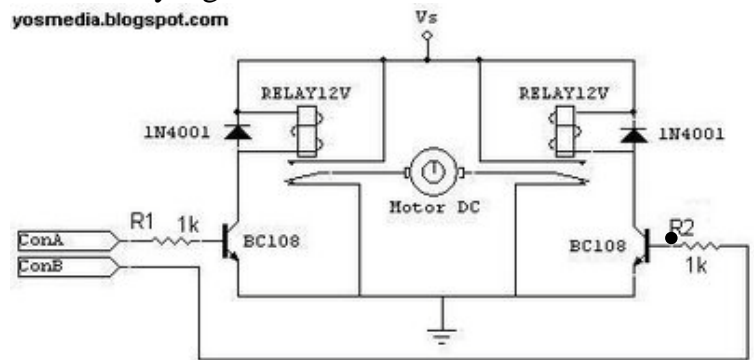

Gambar 2. Rangkaian Driver Motor

\section{MOTOR DC}

Motor DC/arus searah, sebagaimana namanya, menggunakan arus langsung yang tidak langsung/direct-unidirectional. Motor DC digunakan pada penggunaan khusus dimana diperlukan penyalaan torsi yang tinggi atau percepatan yang tetap untuk kisaran kecepatan yang luas. 


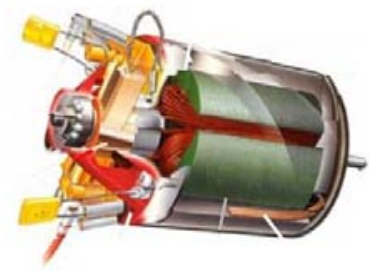

Gambar 3. Motor DC

\section{HEATER}

Heater merupakan alat pemanas yang terbuat dari bahan yang mempunyai hambatan besar. Panasnya ditentukan oleh daya dari heater (kawat nikelin) semakin besar dayanya akan semakin tinggi temperaturnya. Tapi suatu saat temperaturnya akan konstan (tidak akan naik terus) hal ini dikarenakan panas yang dihasilkan sama dengan panas yang hilang ke udara atau dipakai untuk melumerkan plastik, sehingga tidak akan menghancurkan/ merusakkan heater.

\section{MIKROKONTROLER ATMEGA 8535}

Mikrokontroler AVR ATMega8535 merupakan mikrokontroler produksi Atmel dengan 8 KByte In-System Programmable-Flash, 512 Byte EEPROM dan 512 Bytes Internal SRAM. AVR ATMega8535 memiliki seluruh fitur yang dimiliki AT90S8535. Selain itu, konfigurasi pin AVR ATMega8535 juga kompatibel dengan AT90S8535.

\begin{tabular}{|c|c|c|c|c|}
\hline & & & & \\
\hline (XCK/TO) PBO $\square$ & 1 & 40 & PAO & $(A D C 0)$ \\
\hline (T1) PB1 & 2 & 39 & PA1 & (ADC1) \\
\hline (INT2/AINO) PB2 & 3 & 38 & PA2 & (ADC2) \\
\hline (OCO/AIN1) PB3 & 4 & 37 & PA3 & (ADC3) \\
\hline 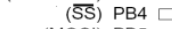 & 5 & 36 & PA4 & (ADC4) \\
\hline (MOSI) PB5 & 6 & 35 & PA5 & (ADC5) \\
\hline (MISO) PB6 & 7 & 34 & $\square$ PA6 & (ADC6) \\
\hline (SCK) PB7 & 8 & 33 & PA7 & (ADC7) \\
\hline RESET & 9 & 32 & AREF & \\
\hline VCC & 10 & 31 & GND & \\
\hline GND & 11 & 30 & $\neg \mathrm{AVCC}$ & \\
\hline XTAL2 & 12 & 29 & PC7 & (TOSC2 \\
\hline XTAL1 & 13 & 28 & PC6 & (TOSC \\
\hline (RXD) PDO & 14 & 27 & PC5 & \\
\hline (TXD) PD1 & 15 & 26 & $\neg \mathrm{PC} 4$ & \\
\hline (INTO) PD2 & 16 & 25 & PC3 & \\
\hline (INT1) PD3 $\square$ & 17 & 24 & $\neg$ PC2 & \\
\hline (OC1B) PD4 & 18 & 23 & PC1 & (SDA) \\
\hline (OC1A) PD5 & 19 & 22 & $\neg \mathrm{PCO}$ & $(\mathrm{SCL})$ \\
\hline (ICP1) PD6 & 20 & 21 & PD7 & (OC2) \\
\hline
\end{tabular}

Gambar 4. Konfigurasi pin ATMega8535

\section{LDR (LIGHT DEPENDENT RESISTOR)}

LDR adalah sebuah resistor dimana nilai resistansinya akan berubah jika dikenai cahaya..

\section{SENSOR SUHU LM 35}

Sensor suhu LM35 merupakan salah satu komponen elektronika yang memiliki fungsi untuk mengubah besaran suhu menjadi besaran listrik dalam bentuk tegangan.

\section{SEVEN SEGMENT}

Seven Segment adalah suatu segmen-segmen yang digunakan menampilkan angka. Seven segmen ini tersusun atas 7 batang LED yang disusun membentuk angka 8 yang penyusunnya menggunakan diberikan lebel dari 'a' sampai 'g' dan satu lagi untuk dot point (DP).
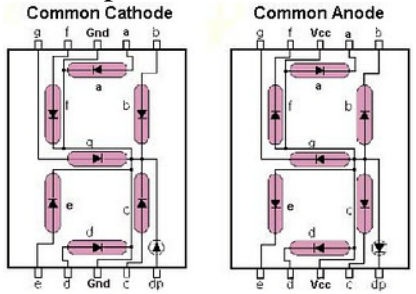

Gambar 5. Common Cathode \& Anode

\section{KEYPAD KONTROL 3X4}

Mikrokontroler sebagai pengendali memerlukan input untuk diolah kemudian mengeluarkan output dari hasil proses. Salah satu media input adalah tombol yang difungsikan untuk membaca masukan/input dari sebuah saklar atau switch yang memberikan suatu nilai logika pada mikrokontroler.

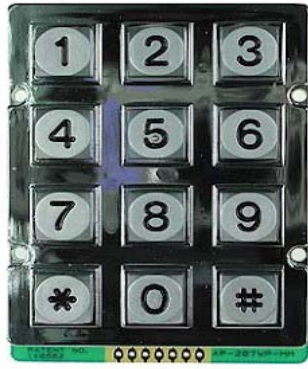

Gambar 6. Keypad 3x4

\section{LCD (LIQUID CRYSTAL DISPLAY)}

LCD Character atau Karakter, adalah LCD yang tampilannya terbatas pada tampilan karakter, khususnya karakter ASCII (seperti karakter-karakter yang tercetak pada keyboard komputer).

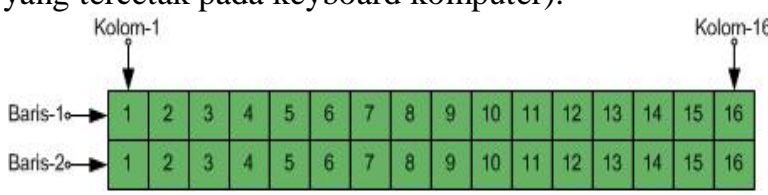

Gambar 7. Alamat Pin LCD

\section{ALUMUNIUM FOIL}

Polietilena tereftalat (disingkat PET, PETE atau dulu PETP, PET-P) adalah suatu resin polimer plastik termoplast dari kelompok poliester.

Polietilena (disingkat PE) (IUPAC: Polietena) adalah termoplastik yang digunakan secara luas oleh konsumen produk sebagai kantong plastik. Sekitar 80 juta metrik ton plastik ini diproduksi setiap tahunnya.

\section{BLOK DIAGRAM SISTEM}

Blok diagram dari "Rangkaian aplikasi mikrokontroler ATmega 8535 dalam Otomatisasi Alat Pencacah Permen Skala Home Industri” ditunjukkan pada gambar 8 . 


\section{CARA KERJA RANGKAIAN}

Sistem kerja aplikasi mikrokontroler ATmega 8535 pada alat pencacah permen skala home industri dapat dilihat pada gambar 9 dan 10 .

Program Mikrokontroler ATMEGA 8535 dan semua rangkaian alat akan bekerja saat menerima input tegangan dari Catu Daya. Keadaan ini disebut keadaan Stand By. Saat Mikrokontoler ATMEGA 8535 mendapat perintah melalui keypad (3x4) yang terhubung dengan Mikrokontroler. Perintah tersebut berupa meng-input suhu berapa heater akan mengepres palstik, berapa jumlah permen yang akan dicacah (dihitung), dan berapak jumlah plastik yang akan dipack (dipress). rancangan yang telah dibuat menjadi sistem yang siap untuk dioperasikan.

Tahap kedua ini yaitu mencakup semua hal yang berkaitan dengan perangkat lunak bagi sistem.

\section{PENGUJIAN SISTEM}

Tabel pengujian dapat dilihat pada Tabel 1. Dari data tersebut dapat dijelaskan bahwa rata-rata suhu kerja optimal adalah sekitar $70^{0}-85^{\circ} \mathrm{C}$. Plastik yang digunakan adalah plastik alumunium foil ukuran $10 \times 15 \mathrm{~cm}$ dan $12 \times 15 \mathrm{~cm}$ jenis PET dan PE tanpa zipper dengan ketebalan 0,8 mikron. Plastik tersebut berbentuk "Pouch". Untuk waktu pegepresan adalah 25 detik secara konstan.

\section{PEMBUATAN ALAT}

Tahap pertama ini meliputi semua proses pembuatan perangkat keras untuk merealisasikan

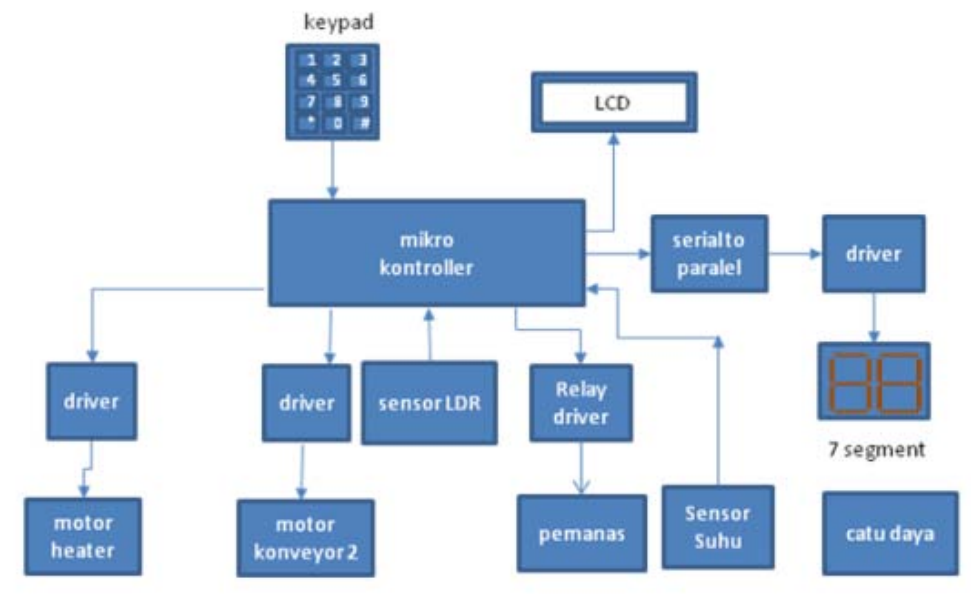

Gambar 8. Blok Diagram Sistem

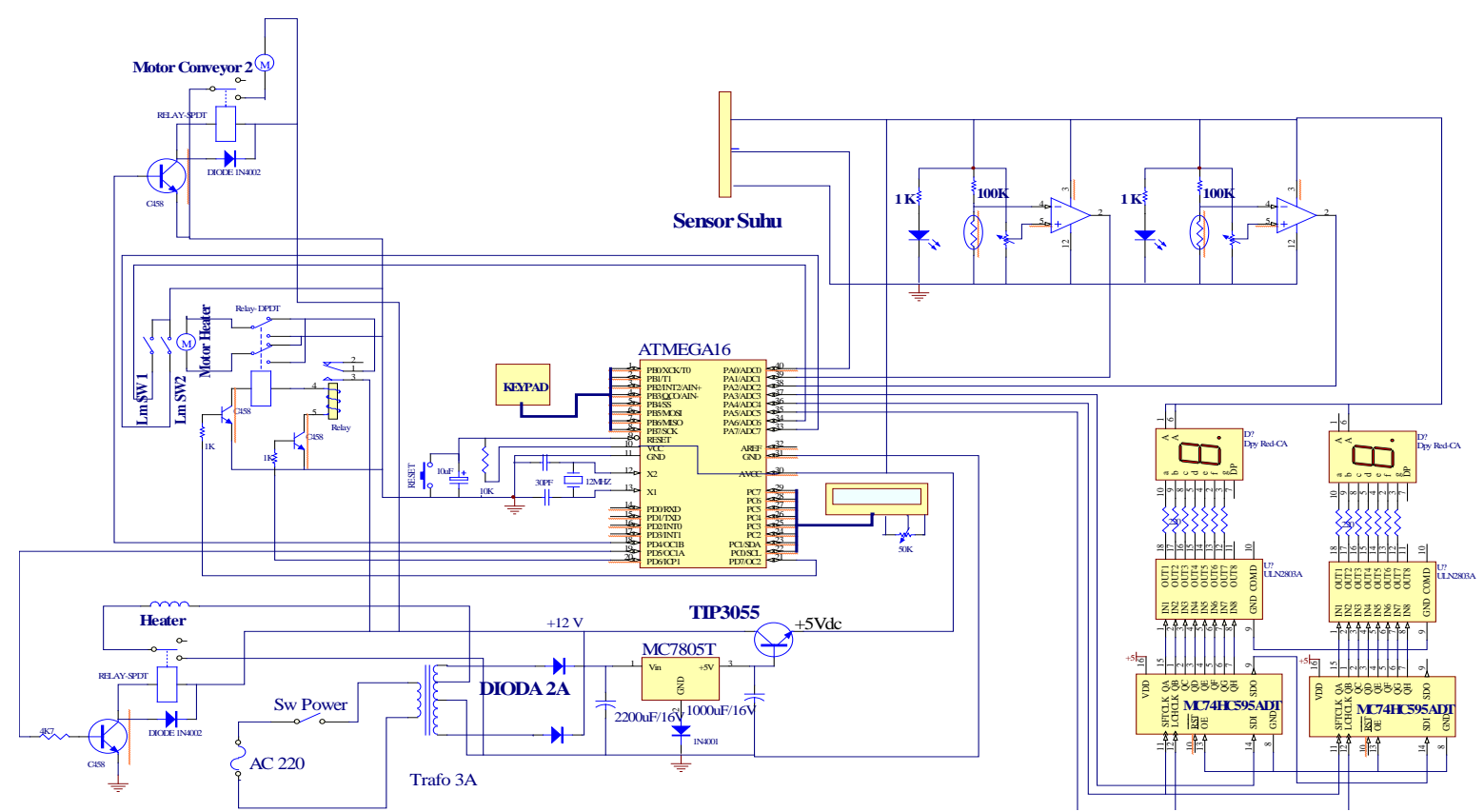

Gambar 9. Rangkaian Keseluruhan Sistem Pengepakan 


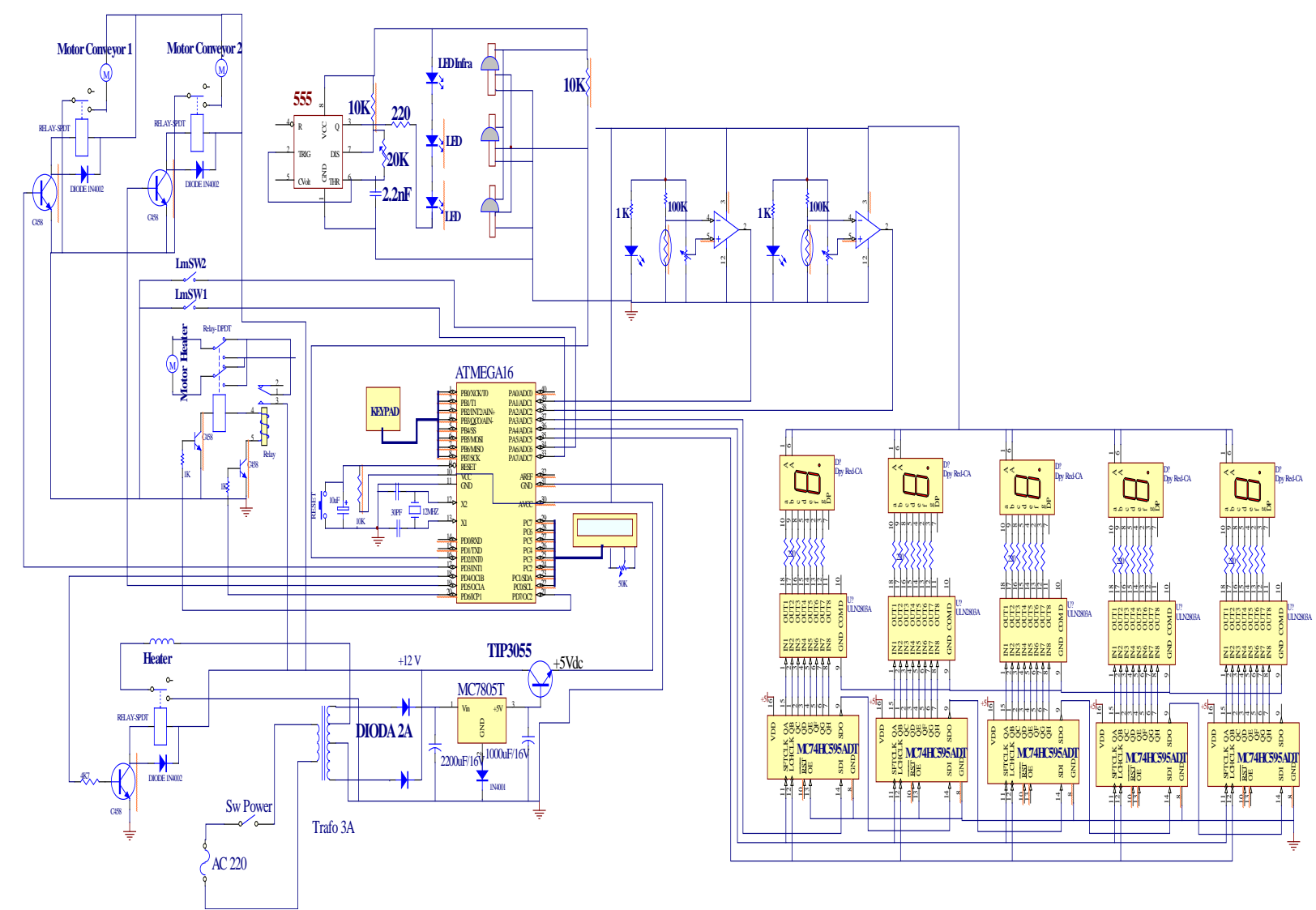

Gambar 10. Rangkaian Keseluruhan Sistem Pencacah dan Pengepakan

Tabel 1. Hasil Pengujian Pengepresan Plastik

\begin{tabular}{|l|l|l|}
\hline No & Suhu Heater $\left({ }^{0} \mathrm{C}\right)$ & Hasil Pengepresan Plastik \\
\hline 1 & $0-5$ & Belum melekat \\
\hline 2 & $5-10$ & Belum melekat \\
\hline 3 & $10-15$ & Belum melekat \\
\hline 4 & $15-20$ & Belum melekat \\
\hline 5 & $20-25$ & Belum melekat \\
\hline 6 & $25-30$ & Belum melekat \\
\hline 7 & $30-35$ & Belum melekat \\
\hline 8 & $35-40$ & Belum melekat \\
\hline 9 & $40-45$ & Belum melekat \\
\hline 10 & $45-50$ & Belum melekat \\
\hline 11 & $50-55$ & Belum melekat \\
\hline 12 & $55-60$ & Belum melekat \\
\hline 13 & $60-65$ & Belum melekat \\
\hline 14 & $65-70$ & Belum melekat \\
\hline 15 & $70-75$ & Melekat Tapi Mudah Dibuka \\
\hline 16 & $75-80$ & Melekat Sulit Dibuka \\
\hline 17 & $80-85$ & Melekat Kuat Sangat Sulit Dibuka \\
\hline 18 & $85-90$ & Plastik Meleleh \\
\hline 19 & $90-95$ & Plastik Meleleh \\
\hline 20 & $95-100$ & Plastik Meleleh \\
\hline
\end{tabular}




\section{KESIMPULAN}

- Suhu kerja optimal adalah sekitar $70^{0}-85^{\circ} \mathrm{C}$.

- Plastik yang digunakan adalah plastik alumunium foil ukuran $10 \times 15 \mathrm{~cm}$ dan 12x15 $\mathrm{cm}$ jenis PET dan PE tanpa zipper dengan ketebalan 0,8 mikron. Plastik tersebut berbentuk "Pouch".

- Untuk waktu pegepresan adalah 25 detik secara konstan.

\section{DAFTAR PUSTAKA}

1. Iswanto, S.T.. 2008. Design dan Implementasi Sistem Embedded Mikrokontroler ATMega8535 dengan Bahasa Basic. Yogyakarta: Gava Media.
2. Malvino, A.P.. 1996. Prinsip-prinsip Elektronika (terjemahan Hanapi Gunawan). Jakarta: Erlangga.

3. Setyadi, Ary. 2010. Bahasa Indonesia dalam Karya Ilmiah. Semarang: Fakultas Ilmu Budaya UNDIP.

4. Sudjadi. 2005. Teori dan Aplikasi Mikrokontroler. Yogyakarta: Graha Ilmu.

5. Wardhana, Lingga. 2006. Mikrokontroler AVR seri ATMEGA Simulasi. Hardware. dan Aplikasi. Yogyakarta: Andi.

6. Widodo Budiharto, S., Si., M.Kom.. 2005. Elektronika Digital dan Mikroprosesor. Yogyakarta: Andi.

7. Zuhal dan zhanggischan. 2004. Prinsip Dasar Elektronika. Gramedia Pustaka Jakarta: Utama. 